\title{
Formation of $\mathrm{BaMgAl}_{10} \mathrm{O}_{17}$ :Eu Phosphor Particles with Spherical Shape and Filled Morphology in the Flame Spray Pyrolysis
}

\author{
Jung Sang CHO, Seung Kwon HONG, Dae Soo JUNG, Jin Man HAN and Yun Chan KANG ${ }^{\dagger}$ \\ Department of Chemical Engineering, Konkuk University, 1 Hwayang-dong, Gwangjin-gu, Seoul 143-701, Korea
}

\begin{abstract}
Fine-sized, spherical $\mathrm{BaMgAl}_{10} \mathrm{O}_{17}: \mathrm{Eu}^{2+}$ phosphor particles with filled morphologies were prepared by flame spray pyrolysis. Precursor particles prepared by flame spray pyrolysis at a low-temperature diffusion flame and a short particle residence time within the diffusion flame were of large size and had hollow structures. On the other hand, precursor particles prepared at optimum preparation conditions were fine sized, had filled structures, and narrow size distributions. The melting of large-sized intermediate particles with hollow structures within the high-temperature diffusion flame formed fine-sized, spherical precursor particles with filled structures. The $\mathrm{BaMgAl}_{10} \mathrm{O}_{17}: \mathrm{Eu}^{2+}$ phosphor particles prepared by flame spray pyrolysis at optimum preparation conditions were fine-sized and had regular morphologies after post-treatment at $1400{ }^{\circ} \mathrm{C}$. The mean size of the $\mathrm{BaMgAl}_{10} \mathrm{O}_{17}$ : $\mathrm{Eu}^{2+}$ phosphor particles was $1.0 \mu \mathrm{m}$. The photoluminescence intensity of fine-sized, spherical $\mathrm{BaMgAl}_{10} \mathrm{O}_{17}$ : $\mathrm{Eu}^{2+}$ phosphor particles with filled structures was higher than that of large-sized phosphor particles with hollow structures excited by the vacuum ultraviolet light at the wavelength, $147 \mathrm{~nm}$.
\end{abstract}

[Received March 2, 2007; Accepted July 19, 2007]

Key-words : Phosphor, Spray pyrolysis, Flame spray pyrolysis, Aluminate

1. Introduction

$\mathrm{BaMgAl}_{10} \mathrm{O}_{17}: \mathrm{Eu}^{2+}$ (BAM:Eu) phosphor, which has a plate-like structure when produced through conventional preparation methods, is an important blue-emitting phosphor for use in the production of plasma display panels (PDPs) and fluorescent lamps (FLs). ${ }^{1)-4)}$ Remarkable developments in the display industry requires improved fine-sized, spherical phosphor particles with high brightness degrees. Many new techniques have been applied in the preparation of this phosphor particle and to control the morphology of its platelike structure. ${ }^{5)-7)}$

Flame spray pyrolysis, which is analogous to conventional spray pyrolysis except for its energy source for drying and decomposition of droplets, is considered a potential process for the preparation of dense particles by melting the particles at a high temperature. ${ }^{8)-14}$ Although flame spray pyrolysis has a shorter residence time than conventional spray pyrolysis using an electronic furnace, dense particles can be produced by melting them at a high temperature, which cannot be achieved in an electronic furnace. A flame using fuel gas such as propane and hydrogen can achieve high temperatures above $2000^{\circ} \mathrm{C}$, and the temperature can be controlled by varying the amounts of fuel gas and oxidizer gas. Flame spray pyrolysis has been performed on the preparation of $\mathrm{BaMgAl}_{10} \mathrm{O}_{17}: \mathrm{Eu}^{2+}$ (BAM:Eu) phosphor particles. Using flame spray pyrolysis, Jung and Kang prepared spherical BAM:Eu phosphor particles with filled morphologies from aluminum polycation spray solutions. ${ }^{9)}$ Chang et al. also prepared BAM:Eu phosphor particles by flame spray pyrolysis at various preparation conditions. ${ }^{10)}$ However, BAM:Eu phosphor particles prepared by flame spray pyrolysis from aqueous spray solutions had hollow and porous morphologies. In addition, the formation mechanism of the BAM:Eu phosphor particles with filled morphologies in flame spray pyrolysis was not studied.

In this work, spherical BAM:Eu phosphor particles with filled morphologies were prepared by flame spray pyrolysis by optimizing the flow rates of fuel, oxidizer, and carrier gases. The formation mechanism of BAM:Eu phosphor particles

\footnotetext{
$\dagger$ Corresponding author; E-Mail: yckang@konkuk.ac.kr
}

with filled morphologies was investigated.

\section{Experiments}

A schematic diagram of the flame spray pyrolysis system is shown in Fig. 1. The flame spray pyrolysis system has a droplet generator, a flame nozzle, a quartz reactor, a particle collector, and a blower. A $1.7 \mathrm{MHz}$ ultrasonic spray generator with six resonators is used to generate droplets, which are carried into the high-temperature diffusion flame by oxygen as the carrier gas. The droplets and particles evaporate, decompose, and melt inside the diffusion flame. Propane, as the fuel, and oxygen, as the oxidizer, create the diffusion flame. The flame nozzle has five concentric pipes. The droplets generated from the precursor solution are supplied to the diffusion flame through the center pipe by different flow rates of the carrier gas. The temperatures of the diffusion flame and the residence time of the particles inside the diffusion flame

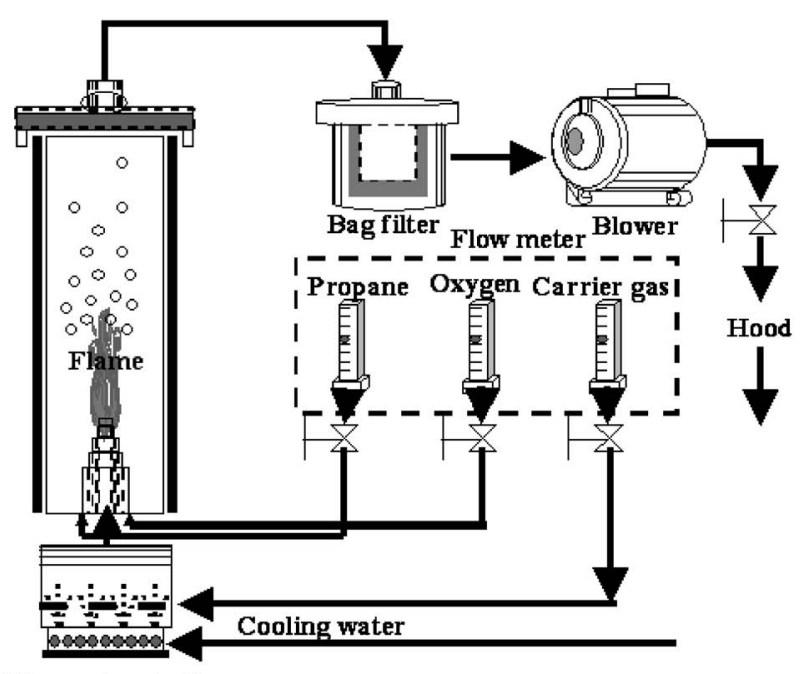

Ultrasonic nebulizer

Fig. 1. Schematic diagram of the flame spray pyrolysis process. 


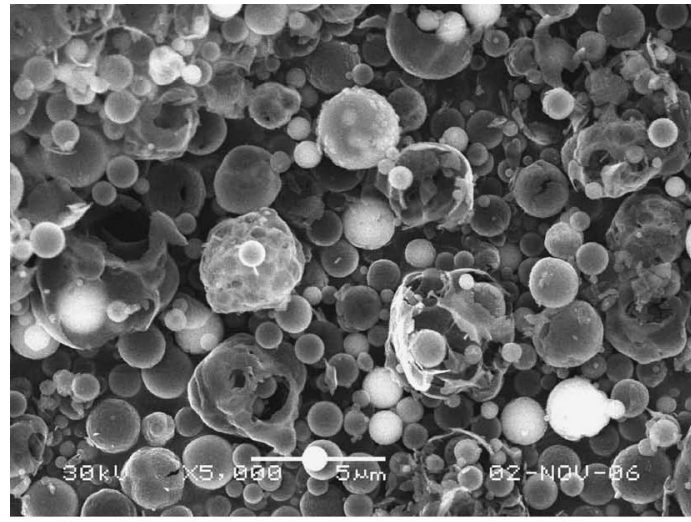

(a) (2-35-10)

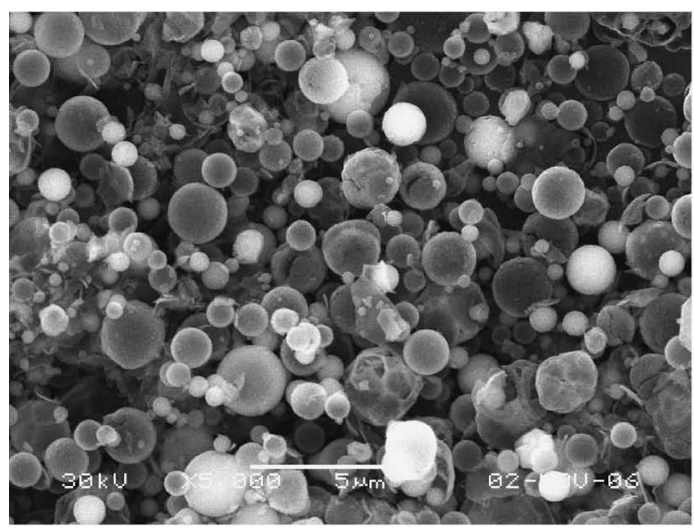

(b) (3-35-10)

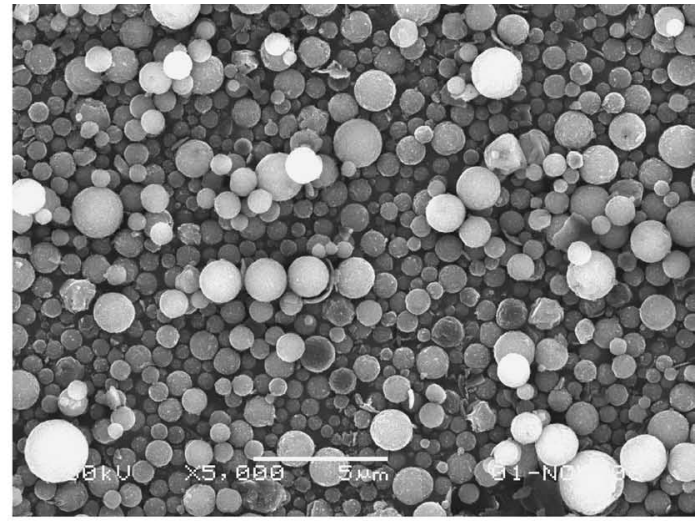

(c) (4-35-10)

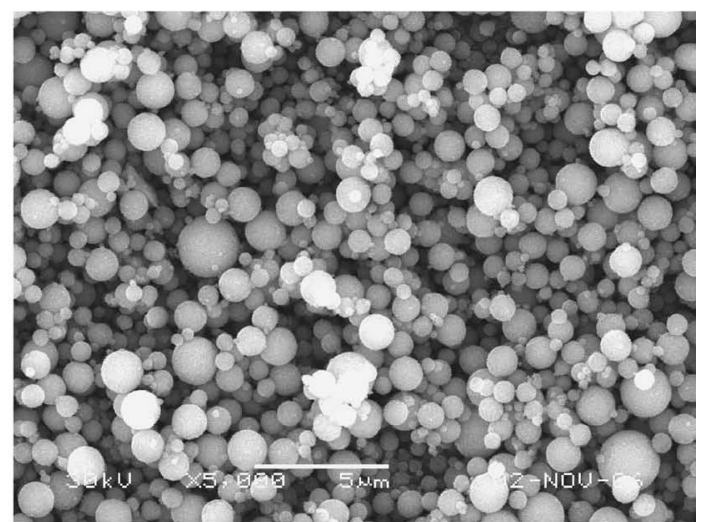

(d) $(4.5-35-10)$

Fig. 2. SEM photographs of the precursor particles prepared at different flow rates of fuel gas (fuel-oxidizer-carrier gas).

are controlled by changing the amounts of the fuel, oxidizer, and carrier gases. The flow rate of the propane used as the fuel gas was changed from 2 to $4.5 \mathrm{~L} / \mathrm{min}$. The flow rate of the oxygen used as the oxidizer gas was fixed at $35 \mathrm{~L} / \mathrm{min}$. The overall solution concentration of the metal precursors was $0.8 \mathrm{M}$. The doping concentration of Eu was fixed at $10 \mathrm{~mol} \%$ of the barium component. The precursor particles obtained by flame spray pyrolysis were post-treated at above $1200^{\circ} \mathrm{C}$ for $3 \mathrm{~h}$ using a $5 \% \mathrm{H}_{2} / \mathrm{N}_{2}$-mixture gas.

The crystal structures of the particles were studied using $\mathrm{X}$-ray diffraction (XRD) with $\mathrm{Cu} \mathrm{K} \alpha$ radiation $(\lambda=1.5418 \times$ $\left.10^{-10} \mathrm{~m}\right)$. The morphologies of the particles were investigated using scanning electron microscopy (SEM). The optical properties of the particles were measured at $147 \mathrm{~nm}$ vacuum ultraviolet (VUV) photoluminescence (PL) spectroscopy excited using a $\mathrm{D}_{2}$ lamp.

\section{Results and discussions}

In flame spray pyrolysis, flow rates of the fuel and carrier gases affected the morphologies of the prepared particles by changing the temperature of the diffusion flame and the residence time of particles within the high-temperature flame. Figure 2 shows the SEM photographs of precursor particles prepared by flame spray pyrolysis at different flow rates of propane, which was used as fuel gas. The flow rates of the propane gas were changed from 2 to $4.5 \mathrm{~L} / \mathrm{min}$. The flow rates of the oxidizer and carrier gases were fixed at 35 and $10 \mathrm{~L} /$ min, respectively. Precursor particles prepared at a low flow rate $(2 \mathrm{~L} / \mathrm{min})$ of the propane gas were of large size and had hollow structures and broad size distributions. Using flame spray pyrolysis, fine-sized droplets were supplied to the hightemperature diffusion flame through a high-flow-rate carrier gas. Therefore, particles prepared by flame spray pyrolysis had hollow and porous structures because of the fast drying and decomposition rates of droplets or particles. On the other hand, precursor particles prepared at a high flow rate $(4.5 \mathrm{~L} /$ min) of propane gas were of fine size and had filled structures and narrow size distributions. The mean size of precursor particles decreased with the increase in the flow rate of propane gas. Particles prepared by flame spray pyrolysis at severe preparation conditions were spherical in shape and had filled structures. The drying and decomposition rates of droplets or particles increased with the increase in the flow rate of the propane gas. Therefore, the formation mechanisms of the particles in the flame spray pyrolysis were different from the flow rates of the propane gas.

Figure 3 shows the SEM photographs of precursor particles prepared at different flow rates of oxygen, which was used as the carrier gas. The flow rates of the fuel and oxidizer gases were fixed at 4.5 and $35 \mathrm{~L} / \mathrm{min}$, respectively. The precursor particles (Fig. 3 (c)) prepared at a high flow rate of the carrier gas had hollow and fractured structures. On the other hand, precursor particles (Fig. 3 (a)) prepared at a low flow rate of the carrier gas had spherical shapes and un-fractured structures. In Figs. 2 and 3, the hollowness of precursor particles increased with the increase in the flow rates of the carrier gas.

Precursor particles prepared by flame spray pyrolysis at optimum preparation conditions were of fine size, had spherical shapes and filled morphologies. In this work, the optimum 


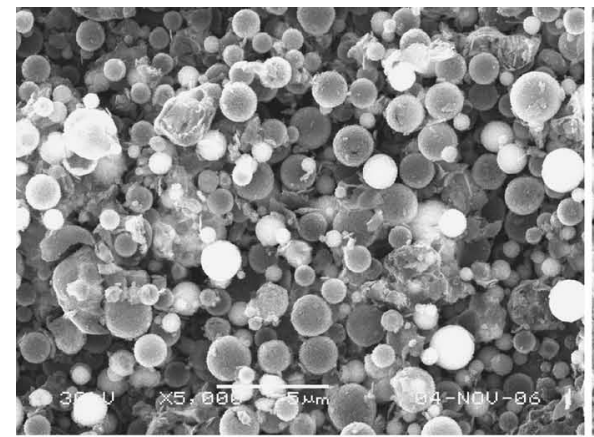

(a) (4.5-35-20)

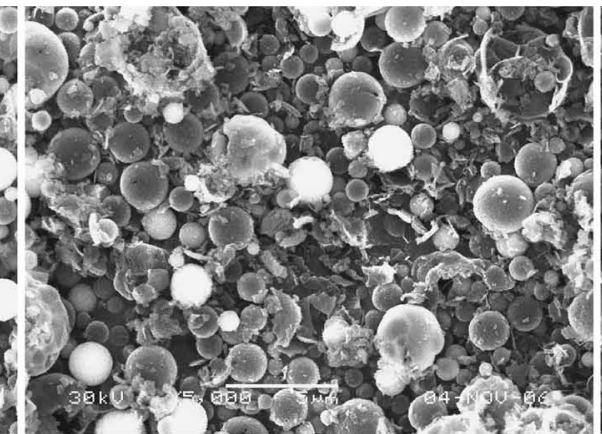

(b) (4.5-35-30)

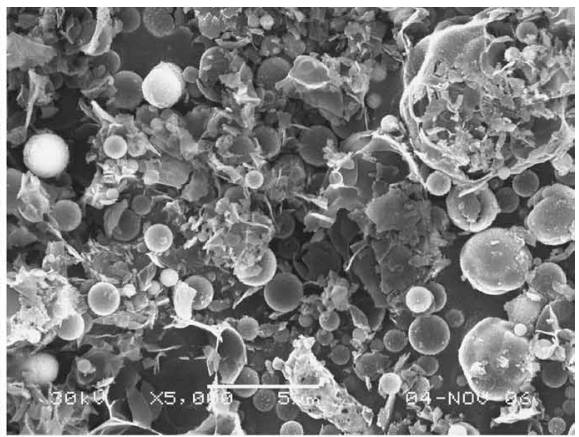

(c) (4.5-35-40)

Fig. 3. SEM photographs of the precursor particles prepared at different flow rates of carrier gas (fuel-oxidizer-carrier gas).

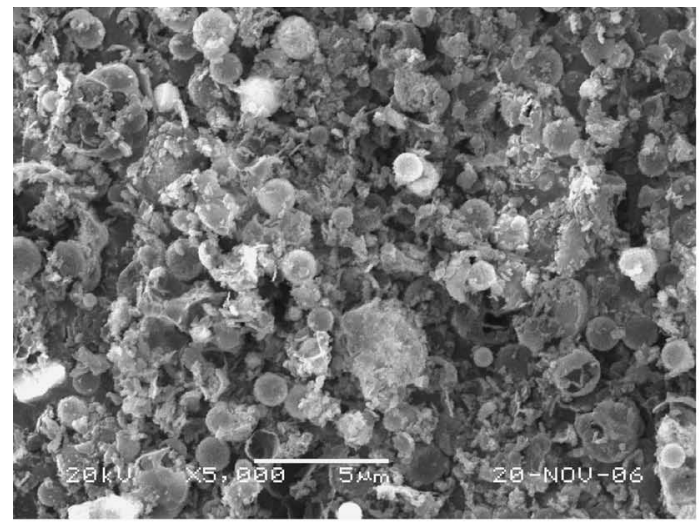

(a) $2 \mathrm{~cm}$

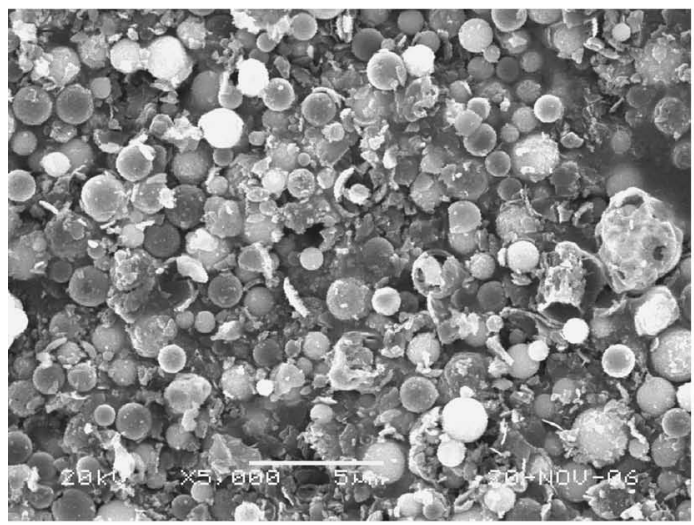

(b) $5 \mathrm{~cm}$

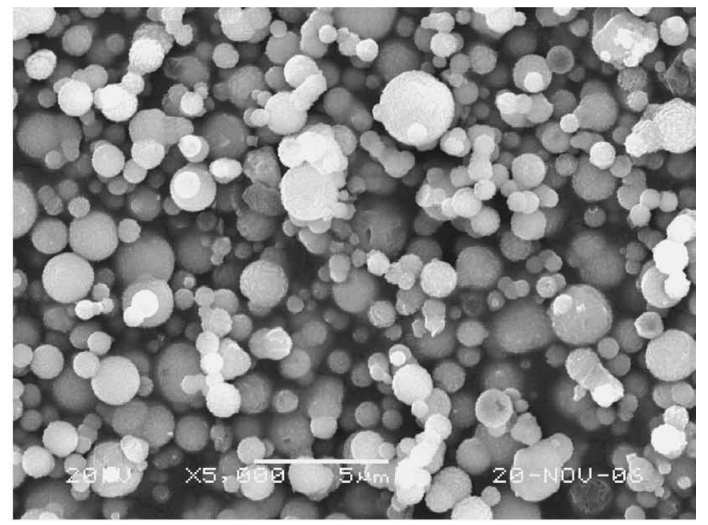

(c) $10 \mathrm{~cm}$

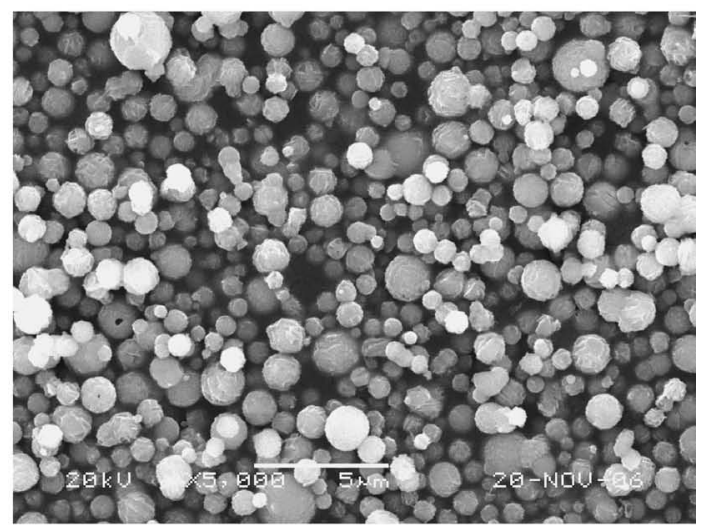

(d) $15 \mathrm{~cm}$

Fig. 4. SEM photographs of the precursor particles collected at different distances from the exit of droplets.

flow rates of the fuel and carrier gases were 4.5 and $10 \mathrm{~L} / \mathrm{min}$, respectively, in which the length of the diffusion flame was $20 \mathrm{~cm}$. To understand the formation mechanism of the finze-sized precursor particles with filled morphologies in the flame spray pyrolysis at optimum preparation conditions, the characteristics of the particles collected at different distances from the droplets' exit were investigated. Figure 4 shows SEM photographs of particles collected at different distances from droplets' exit. Particles collected outside droplets' exit had hollow and fractured structures. Particles collected at a distance of $5 \mathrm{~cm}$ from the exit of the droplets also had hollow and fractured morphologies. On the other hand, particles collected at a distance of $15 \mathrm{~cm}$ from the exit of the droplets were spher- ical and of fine size, and had filled morphologies. The plausible formation mechanism of fine-sized, spherical particles with filled morphologies under the optimum condition was shown in Fig. 5. The intermediate particles collected at short distances from the exit of the droplets had hollow and thin wall structures because of the fast drying and decomposition rates of the droplets or particles. The spherical intermediate particles with filled structures were formed by melting the large-sized particles with hollow structures. Finally, the finesized, spherical crystallized precursor particles with filled structures were formed in the flame spray pyrolysis. The melting of intermediate particles within the diffusion flame did not occur at a low temperature. Therefore, as shown in Fig. 2, the 


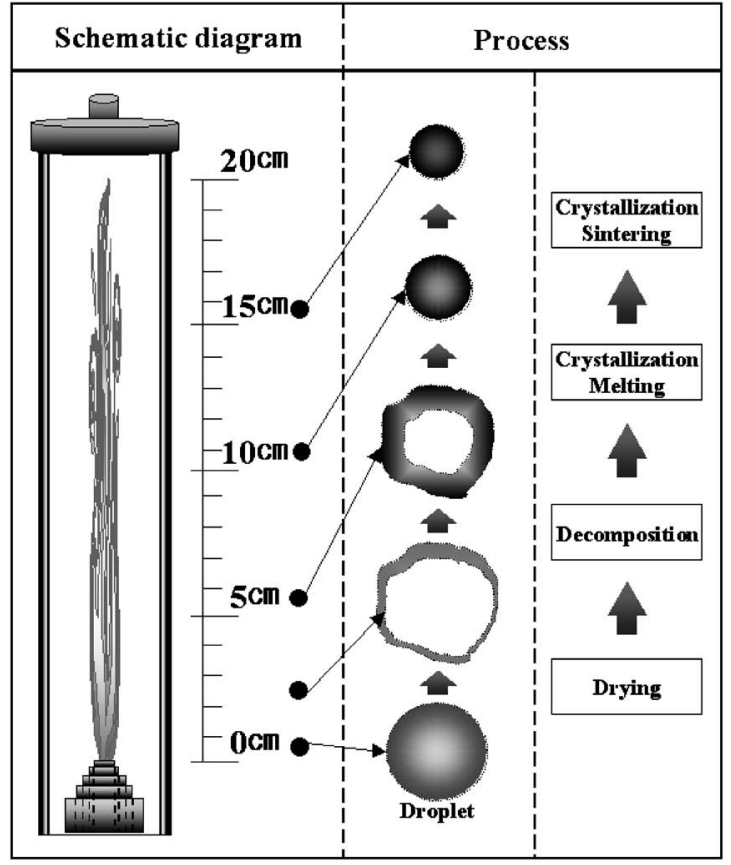

Fig. 5. Formation mechanism of the precursor particle in the flame spray pyrolysis.

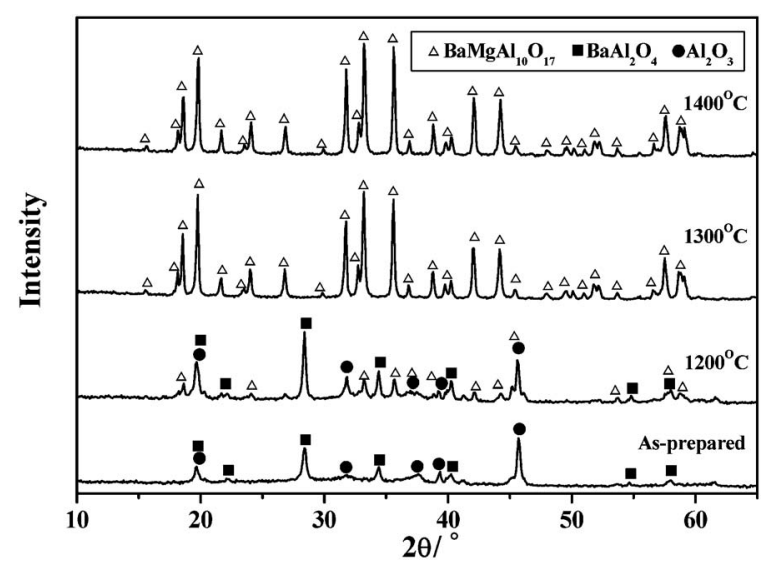

Fig. 6. XRD spectra of the particles post-treated at different temperatures.

particles prepared at a low flow rate of the propane gas were of large size and had hollow and porous structures. The particles prepared at a high flow rate of the carrier gas in Fig. 3 were of large size and had hollow structures because of the short residence time of the particles inside the high-temperature diffusion flame.

The crystal structures of the precursor and post-treated particle are shown in Fig. 6. The precursor particles obtained by flame spray pyrolysis had mixed $\mathrm{BaAl}_{2} \mathrm{O}_{4}$ and $\mathrm{Al}_{2} \mathrm{O}_{3}$ crystal structures. The short residence times of the particles inside the high-temperature diffusion flame of the particles did not form crystalline BAM phase. The peaks of the BAM phase appeared at the post-treatment temperature of $1200^{\circ} \mathrm{C}$. The particles post-treated at temperatures above $1300^{\circ} \mathrm{C}$ under a reducing atmosphere had pure crystal structures of the BAM phase in the XRD spectra. The photoluminescence intensities of the phosphor particles under vacuum ultraviolet increased

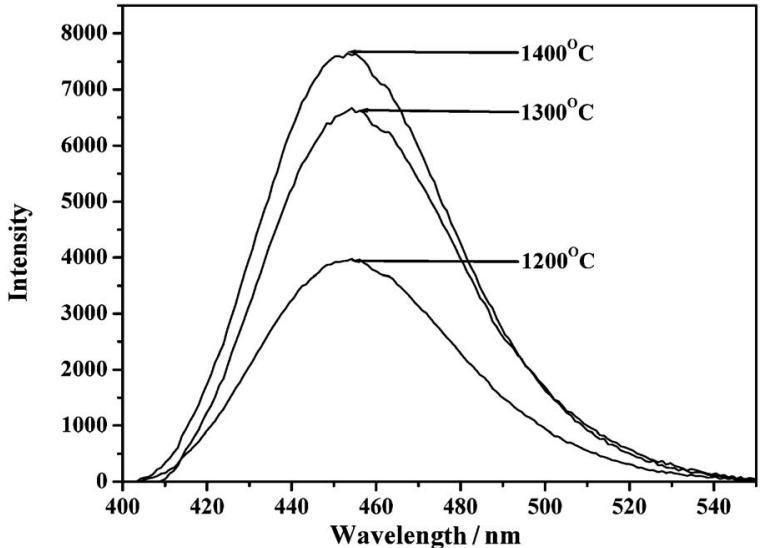

Fig. 7. Photoluminescence spectra of the phosphor particles posttreated at different temperatures.

with the increase in post-treatment temperatures, as shown in Fig. 7.

Figure 8 shows the SEM photographs of post-treated BAM: $\mathrm{Eu}$ phosphor particles. Precursor particles obtained by flame spray pyrolysis at different flow rates of the carrier gas were post-treated at a temperature of $1400^{\circ} \mathrm{C}$ under a reducing atmosphere. The flow rates of the fuel and oxidizer gases were fixed at 4.5 and $35 \mathrm{~L} / \mathrm{min}$, respectively. The BAM:Eu phosphor particles obtained from fine-sized, spherical precursor particles (Fig. 2(d)) with filled morphologies were of fine size and had regular morphologies after post-treatment. The spherical shapes of the precursor particles were maintained after post-treatment at a high temperature. The mean size of the BAM:Eu phosphor particles measured from the SEM photograph was $1.0 \mu \mathrm{m}$. On the other hand, the BAM:Eu phosphor particles obtained from the precursor particles (Fig. 3(c)) with hollow and fractured structures were of large size and had irregular morphologies. The hollowness and mean size of the BAM:Eu phosphor particles increased with the increase in the flow rates of the carrier gas. In the XRD spectra, the posttreated phosphor particles had a pure BAM phase and similar crystallinities regardless of the flow rates of the carrier gas. Figure 9 shows the EDX spectra of the precursor and posttreated particles. The compositions of the precursor and posttreated particles were similar in comparison with the composition of the spray solution. The deviations in the compositions of the particles with the evaporation of some volatile components did not occur in the preparation of the BAM:Eu phosphor particles by flame spray pyrolysis. The photoluminescence characteristics of phosphor particles prepared by flame spray pyrolysis at different flow rates of the carrier gas under vacuum ultraviolet (VUV, $147 \mathrm{~nm}$ ) are shown in Fig. 10. A single peak of the wide spectrum was observed at $450 \mathrm{~nm}$ due to the $5 \mathrm{~d}-4 \mathrm{f}$ transition of $\mathrm{Eu}^{2+}$. The photoluminescence intensities of fine-sized, spherical phosphor particles with filled structures were higher than those of large-sized phosphor particles with hollow structures.

\section{Conclusion}

BAM:Eu phosphor particles were prepared by flame spray pyrolysis at various fuel, oxidizer, and carrier gas flow rates. The formation mechanism of the BAM:Eu phosphor particles in flame spray pyrolysis was investigated. The precursor particles prepared by flame spray pyrolysis at optimum preparation conditions were of fine size and spherical and had filled mor- 


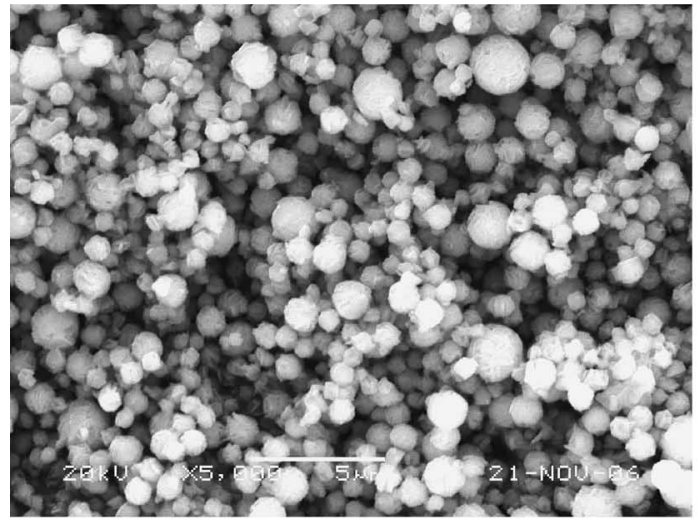

(a) (4.5-35-10)

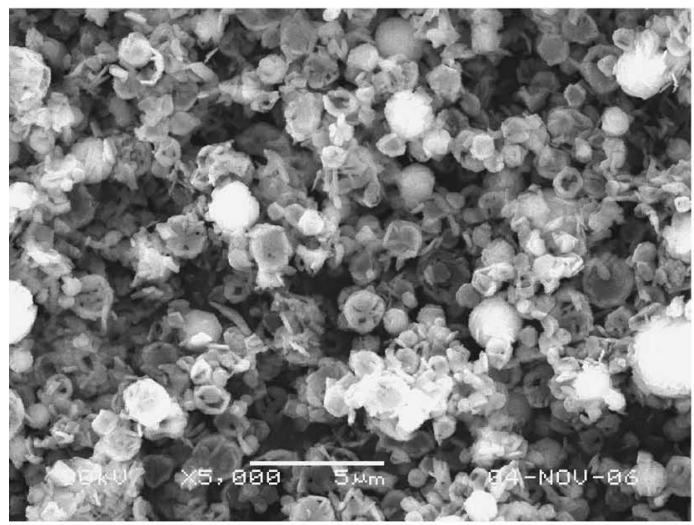

(b) (4.5-35-20)

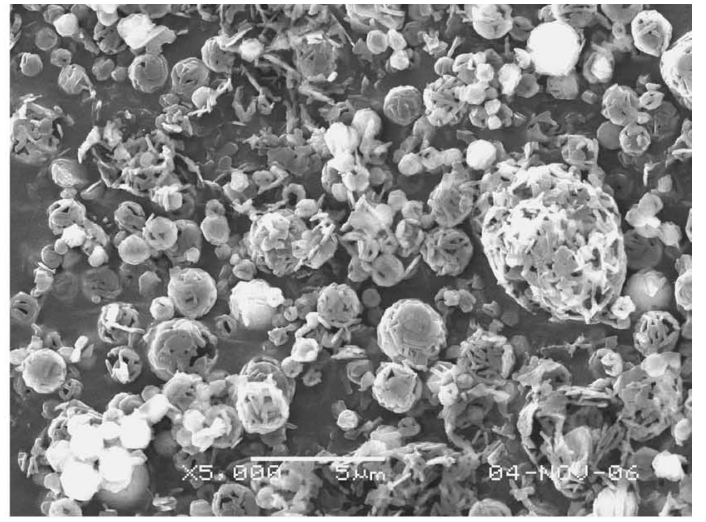

(c) (4.5-35-30)

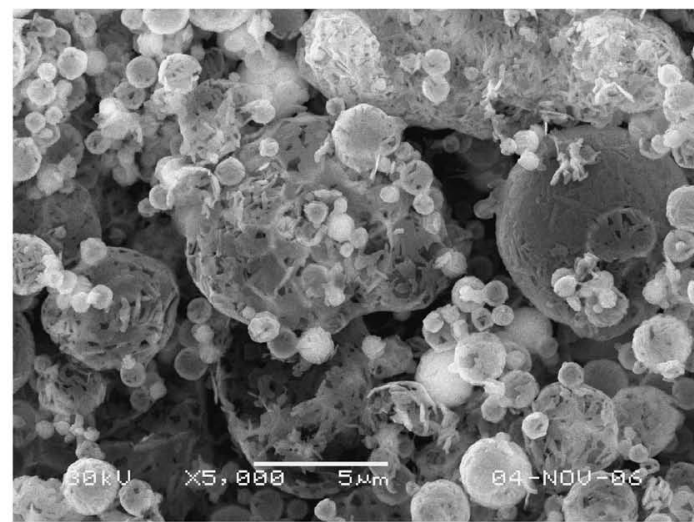

(d) (4.5-35-40)

Fig. 8. SEM photographs of the BAM phosphor particles (fuel gas-oxidizer-carrier gas).

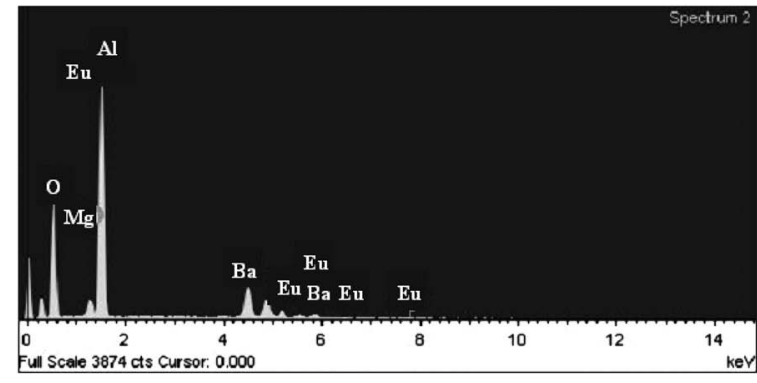

(a) precursor

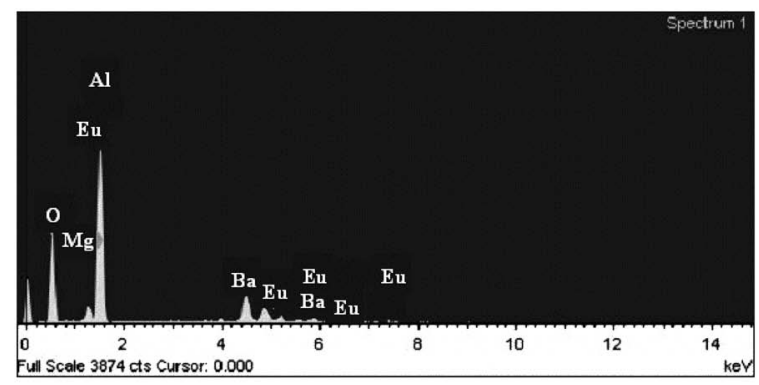

(b) post-treated

Fig. 9. EDX spectra of the precursor and post-treated particles.

phologies. In this work, the optimum flow rates of the fuel, oxidizer, and carrier gases were $4.5,35$, and $10 \mathrm{~L} / \mathrm{min}$, respec-

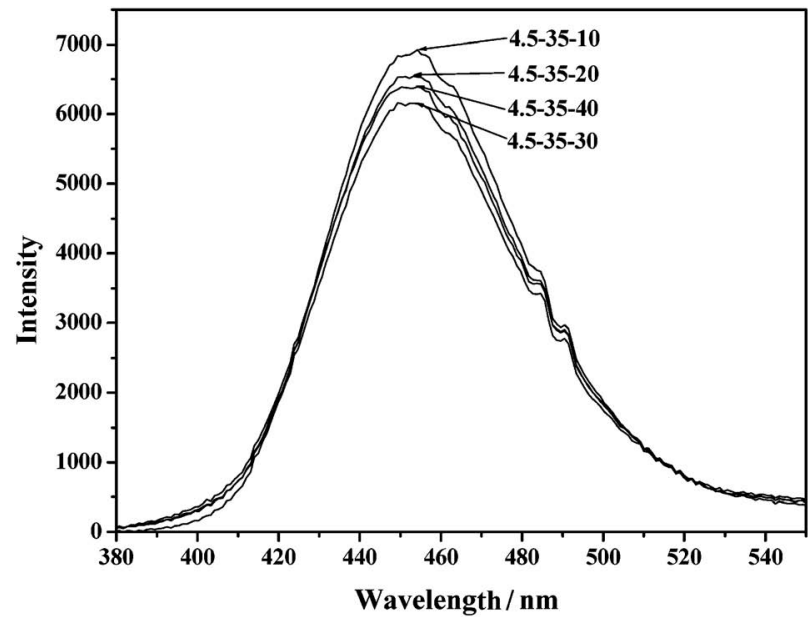

Fig. 10. Photoluminescence spectra of the BAM phosphor particles.

tively, in which the diffusion flame length was $20 \mathrm{~cm}$. The BAM:Eu phosphor particles obtained by flame spray pyrolysis were of fine size and had regular morphologies after posttreatment. The photoluminescence intensities of the BAM:Eu phosphor particles prepared by flame spray pyrolysis were investigated under vacuum ultraviolet excitation.

Acknowledgements This work was supported by the Korea Research Foundation Grant funded by the Korean Government 
(R08-2004-000-10160-0).

\section{References}

1) D. Ravichandran, R. Roy, W. B. White and S. Erdei, J. Mater. Res., 12, 819-824 (1997).

2) D. Ravichandran, R. Roy, P. Ravindranathan and W. B. White, J. Am. Ceram. Soc., 82, 1082-1084 (1999).

3) K. Yokota, S. X. Zhang, K. Kimura and A. Sakamoto, J. Lumin., 92, 223-227 (2001).

4) K. C. Mishra, M. Raukas, A. Ellens and K. H. Johnson, J. Lumin., 96, 95-105 (2002).

5) C. R. Ronda and B. M. Smets, J. Electrochem. Soc., 136, 570-573 (1989).

6) S. Oshio, K. Kitamura, T. Shigeta, S. Horii, T. Matsuoka, S. Tanaka and H. Kobayashi, J. Electrochem. Soc., 146, 392-399 (1999).
7) S. Oshio, T. Matsuoka, S. Tanaka and H. Kobayashi, J. Electrochem. Soc., 145, 3898-3903 (1998).

8) Y. C. Kang, D. J. Seo, S. B. Park and H. D. Park, Mater. Res. Bull., 37, 263-269 (2002).

9) K. Y. Jung and Y. C. Kang, Mater. Lett., 58, 2161-2165 (2004).

10) H. K. Chang, I. W. Lenggoro, T. Ogi and K. Okuyama, Mater. Lett., 59, 1183-1187 (2005).

11) D. Dosev, B. Guo and I. M. Kennedy, J. Aerosol Sci., 37, 402-412 (2006).

12) A. Camenzind, R. Strobel and S. E. Pratsinis, Chem. Phys. Lett., 415, 193-197 (2005).

13) A. I. Y. Tok, F. Y. C. Boey, S. W. Du and B. K. Wong, Mater. Sci. Eng. B, 130, 114-119 (2006).

14) T. Suzuki, Y. Ohishi and T. Tani, Mater. Sci. Eng. B, 128, 151-155 (2006). 